\title{
Effective control of Johne's disease in large Czech dairy herds
}

\author{
Věra Fichtelová ${ }^{1 凶}$, Alena Králová1, \\ Vladimír Babák ${ }^{2}$, Kamil Kovařčík ${ }^{1}$ \\ ${ }^{1}$ Department of Infectious Diseases and Preventive Medicine, \\ ${ }^{2}$ Department of Microbiology and Antimicrobial Resistance, \\ Veterinary Research Institute, 621 00, Brno, Czech Republic \\ fichtelova@vri.cz
}

Received: August 24, 2021 Accepted: December 20, 2021

\begin{abstract}
Introduction: Johne's disease, caused by infection with Mycobacterium avium subsp. paratuberculosis (MAP), causes economic losses in dairy herds due to reduced milk production and premature culling. A test-and-cull strategy coupled with changes in calf rearing management preventing new infections has been introduced into infected herds to control MAP prevalence. This study appraised the effectiveness of these practice changes. Material and Methods: In 19 large dairy herds (of a median 470 milk-producing cows), implementing MAP control measures for 3-7 years, a serum ELISA was used to detect infected cows in their dry-off period. The number of ELISA-positive animals per year (EPAY) was calculated and statistical analysis was used to test whether the EPAY total decreased during the control period and to analyse the EPAY in relationship to the duration of the control programme. Results: Statistical support was found for a decrease of EPAY over time $(\mathrm{P}<0.01$, odds ratio 0.756$)$ and in 14 herds a significant fall in the percentages of EPAY during the test period $(\mathrm{P} \leq 0.05)$ was noted. Conclusion: Our results demonstrated the effectiveness of the control measures in place to reduce MAP infection in herds with initial EPAY $\geq 3.36 \%$. The missing decreasing trend in the remaining five herds with low average initial EPAY suggested the need for additional measures to reduce the number of infected animals in these herds.
\end{abstract}

Keywords: dairy cattle, Johne's disease, serum ELISA, MAP control.

\section{Introduction}

The causative agent of Johne's disease (paratuberculosis), a chronic granulomatous enteritis of ruminants, is Mycobacterium avium subsp. paratuberculosis (MAP). In dairy herds, the infection causes economic losses predominantly due to reduced milk production and premature culling of infected animals $(8,20,23)$. Horizontal and vertical infection is possible, with horizontal infection being more relevant (17). The probability of dams delivering infected calves increases with the disease progression (25). Susceptible animals are infected through bacteria suckled in colostrum or milk or by ingestion of MAP present in environments contaminated with faeces of infected adult cows (21). Progression of infection is in four distinct stages: latent, subclinical, clinical, and advanced. After a long latent period lasting two or more years, infected animals start to shed MAP in their faeces, with the highest number of
MAP shed by animals in the clinical and advanced stages of infection. Nevertheless, a small number of bacteria are shed intermittently before the onset of clinical signs by subclinically infected cows (16). Clinical manifestations of wasting in the last two stages are accompanied by reduced milk production, weight loss, diarrhoea, and/or eventually by death.

Control programmes introduced into herds manage the infected animals and prevent new infections $(2,24)$. Shedding animals should be detected and removed from the herd (a test-and-cull strategy) as they excrete MAP in their faeces, contaminating the environment and being a source of infection for susceptible animals. Newborn calves are most susceptible to infection (26) and measures should be implemented during calving to prevent these animals from contact with MAP-contaminated adult faeces. The low transmission rate in well-managed herds allows a delayed removal of infected animals and culling of only high shedders (14). In addition to the 
transmission rate, the effectiveness of control measures implemented in infected herds is also affected by the prevalence of infected adults, and in low-prevalence herds, the offspring of infected dams should be removed (5).

Current diagnostic tests include ELISA detecting specific anti-MAP antibodies, faecal culture, and direct faecal PCR detecting MAP in faeces $(1,4,18)$. The ELISA test is widely used for herd screening in many countries (9). The mean sensitivity value of ELISA to detect infected cows is relatively low (0.46), but increases with the progression of infection to 0.71 for animals showing clinical signs (18). During infection, MAP shedding precedes the presence of antibodies (16), and tests detecting MAP can thus identify infected animals at an earlier (subclinical) stage of infection.

There are approximately 359,000 dairy cows in the Czech Republic and almost 50\% of them are kept in herds of more than 500 head. No grazing of dams, artificial insemination and calving throughout the year are typical of dairy farm management. Animals are divided into permanent groups according to their age, and milk-producing cows and young cattle are housed separately. The MAP prevalence among dairy cattle is unknown. The only study performed revealed $11.5 \%$ of 786 tested bulk tank milk samples to be positive in ELISA, suggesting a relatively large number of herds with high within-herd prevalence (13). Recently, attempts have been made to introduce a MAP certification programme into dairy herds. To evaluate the infection status of large Czech dairy herds, environmental sampling and MAP qPCR detection were suggested (7). The implementation of control measures or retesting every six months is recommended to farmers respectively with infected herds or with uninfected herds. Control measures consist of testing dams before calving by serum ELISA, removing ELISA-positive cows at the latest at the end of the forthcoming lactation, extracting calves of dams with high ELISA results and reducing the infection transmission rate. Farmers can decide whether to introduce the recommended control measures into their herds because MAP control is voluntary.

The aim of our study was to evaluate the effectiveness of control measures introduced into large Czech dairy herds to reduce the number of MAP infected animals.

\section{Material and Methods}

Herds. The herds in the study were selected based on their past known positive status for MAP infection as determined by the detection of animals with serum antibodies to MAP and/or detection of MAP in the environment or faeces. The farmers were aware of the MAP-positive herd status and showed willingness to follow the recommended measures to control MAP infection in their herds. Nineteen free-stall dairy herds (fifteen of Holstein cattle and four of Czech Fleckvieh cattle) with median size of 470 milk-producing cows (ranging from 110 to 920 cows) were included in the study (Table 1).

Artificial insemination, calving throughout the whole year, breeding of replacement heifers exclusively from herd stock and no grazing are the methods used to manage the herds. Newborn calves are housed in huts, maintained later in permanent groups according to their age and housed in collective pens, located on distant farms for young cattle. Heifers return to the dairy farm in late pregnancy (1-3 months before calving).

Serum antibody testing. Before delivering their second calves as three-year-old or older cows, all gravid animals in the herd had a blood sample drawn six to two weeks before calving. Serum samples were screened for antibodies to MAP using the ID Screen Paratuberculosis indirect screening test (IDVet, Montpellier, France). The relative amount of $\mathrm{Ab}$ in bovine serum samples was calculated by reference to the positive control (expressed as sample to positive ratio, $\mathrm{S} / \mathrm{P}$ ) and results were classified according to the manufacturer's guidance as follows: positive if $\mathrm{S} / \mathrm{P} \geq 0.7$, negative if $\mathrm{S} / \mathrm{P} \leq 0.6$ and doubtful if $0.6<\mathrm{S} / \mathrm{P}<0.7$. Doubtfully tested cows were considered ELISA-positive only if they were retested positive in the next year. The number of ELISA-positive animals detected per year (EPAY) was calculated. Every cow was tested once during each lactating period. If a cow tested positive by serum ELISA in a given previous year, it was not included in the study the next year (applicable to cows tested ELISA-positive and not removed from the herd).

MAP control measures. Besides antibody testing of dams before calving (as described above), farm owners were recommended to implement the following control measures to reduce MAP infection in their herds: separate calving of ELISA-positive dams, removal of newborn calves from maternity pens as soon as possible (in $<2 \mathrm{~h}$ ), feeding of colostrum and/or milk from ELISAnegative dams (milk replacer instead of raw milk is recommended), removal of strongly ELISA-positive $(\mathrm{S} / \mathrm{P}>1.6)$ dams immediately after delivering a calf, not using calves born to these dams as replacement heifers, and no fertilisation and culling of moderately and weakly ELISA-positive cows $(\mathrm{S} / \mathrm{P} \leq 1.6)$ at the latest at the end of the forthcoming lactation period. Cows with an $\mathrm{S} / \mathrm{P}$ below 1.6 can be kept in a herd with a high number of ELISA-positive cows for further lactation only to avoid the need to purchase replacement heifers. In addition, clinically affected animals showing signs of MAP infection are to be tested after the onset of clinical signs by serum ELISA and/or direct faecal PCR or faecal cultivation.

The control measures were implemented in the study herds for different periods of time ranging from three to seven years (Table 1).

Statistical analysis. For each of the 19 farms, whether the EPAY decreased during the implementation of control measures in the herd was evaluated using a chi-squared $\left(\chi^{2}\right)$ test for such a trend. 
The relationship of EPAY to the duration of the control programme was analysed using a generalised non-linear model (linear logit link function, for binomial data distribution). The seventh year was excluded from the model, as it was atypical due to the low number of animals examined. Moreover, these animals had come from only three farms, of which two had a relatively high number of ELISA-positive animals. Statistical analyses were performed using STATISTICA 13.2 software (Dell Software, Round Rock, TX, USA). Values for P of $<0.05$ were considered to indicate statistical significance.

\section{Results}

Incidence of ELISA-positive animals in herds. During the control period, a total of 42,133 serum samples from 19 herds were examined, and 1,687 (4\%) tested positive.

The percentage of EPAY was calculated from the ELISA results; the initial and final percentages determined at the beginning and at the end of the study period, are shown in Table 1 . The initial percentages ranged from 0.82 to 23.05 (median $7.65 \%$ ). Proportions higher than $10 \%$ EPAY were detected in six herds. In another six herds, this proportion did not exceed $10 \%$ but did exceed 5\%. Lower than 5\% EPAY was observed in the remaining seven herds. The final percentages ranged from 0 to $7.57 \%$ (median $1.90 \%$ ). More than $2 \%$ of animals were ELISA-positive at the study end in eight herds, and the EPAY decreased to below 1\% during the testing period in only three herds.

When every individual ELISA-positive cow was not removed from the herd, the average number of these animals which were retested in the subsequent dry period ranged from $3.20 \%$ to $41.31 \%$ (median $14.99 \%$ ). All ELISA-positive cows were removed before the next ELISA testing in four herds. The highest percentages of ELISA-positive animals kept the next lactation were in herds nos 19 and 11 and were $36.39 \%$ and $41.31 \%$, respectively.

Statistical analysis. The results of the $\chi^{2}$ test for a trend of decreasing EPAY during the control period are given in Table 2. In 14 out of the 19 tested herds, a significant decrease in percentages of EPAY was detected during the test period $(\mathrm{P} \leq 0.05)$. In the remaining five herds, no decreasing trend of EPAY $(\mathrm{P}>0.05)$ was detected. The initial percentages of EPAY were $2.90-23.05 \%$ (median $9.32 \%$ ) and $0.82-3.36 \%$ (median 2.20\%), for herds respectively with and without a detected decreasing trend.

The statistically supported decrease of EPAY over time was confirmed by a generalised non-linear model $(\mathrm{P}<0.01)$ (Fig. 1). The odds ratio (OR) derived from the model was 0.756 .

Table 1. Characteristics of 19 studied herds and ELISA results during implementation of MAP control measures

\begin{tabular}{|c|c|c|c|c|c|}
\hline Herd & $\begin{array}{c}\text { Number of lactating } \\
\text { cows in the herd }\end{array}$ & $\begin{array}{c}\text { Control period } \\
\text { in years } \\
\end{array}$ & $\begin{array}{c}\text { Initial percentage } \\
\text { of EPAY }\end{array}$ & $\begin{array}{c}\text { Final percentage } \\
\text { of EPAY }\end{array}$ & $\begin{array}{c}\text { Average percentage } \\
\text { of retested EPAY }\end{array}$ \\
\hline 1 & 470 & 4 & 12.86 & 3.88 & 16.84 \\
\hline 2 & 284 & 6 & 0.82 & 0 & 0 \\
\hline 3 & 330 & 6 & 9.42 & 1.11 & 0 \\
\hline 4 & 432 & 3 & 2.20 & 2.96 & 0 \\
\hline 5 & 535 & 4 & 3.36 & 2.00 & 8.33 \\
\hline 6 & 920 & 6 & 7.65 & 2.32 & 3.20 \\
\hline 7 & 423 & 6 & 2.53 & 1.53 & 4.79 \\
\hline 8 & 390 & 5 & 7.04 & 1.90 & 8.23 \\
\hline 9 & 435 & 6 & 10.04 & 0.90 & 8.16 \\
\hline 10 & 570 & 4 & 2.90 & 1.24 & 23.67 \\
\hline 11 & 590 & 4 & 7.34 & 2.76 & 41.31 \\
\hline 12 & 600 & 7 & 10.66 & 0.20 & 22.28 \\
\hline 13 & 730 & 3 & 3.80 & 1.73 & 0 \\
\hline 14 & 613 & 3 & 11.42 & 4.65 & 21.17 \\
\hline 15 & 550 & 5 & 8.11 & 2.20 & 27.33 \\
\hline 16 & 760 & 6 & 2.05 & 1.95 & 13.13 \\
\hline 17 & 188 & 4 & 9.22 & 1.49 & 9.40 \\
\hline 18 & 110 & 7 & 17.20 & 3.45 & 29.21 \\
\hline 19 & 220 & 7 & 23.05 & 7.57 & 36.39 \\
\hline
\end{tabular}

EPAY - ELISA-positive animals detected per year 
Table 2. Data and results of $\chi^{2}$ test for a trend of decreasing number of ELISA-positive animals tested per year during the control period

\begin{tabular}{|c|c|c|c|c|}
\hline Herd & $\begin{array}{l}\text { Total number of } \\
\text { tested animals }\end{array}$ & $\begin{array}{c}\text { Total number of } \\
\text { ELISA-positive } \\
\text { animals }\end{array}$ & $\begin{array}{l}\text { Percentage of } \\
\text { ELISA-positive } \\
\text { animals }\end{array}$ & Trend \\
\hline 1 & 1,425 & 117 & 8.21 & $\mathrm{P}<0.01$ \\
\hline 2 & 1,341 & 12 & 0.89 & $\mathrm{P}>0.05$ \\
\hline 3 & 2,271 & 88 & 3.87 & $\mathrm{P}<0.01$ \\
\hline 4 & 871 & 20 & 2.30 & $\mathrm{P}>0.05$ \\
\hline 5 & 1,922 & 47 & 2.45 & $\mathrm{P}>0.05$ \\
\hline 6 & 4,852 & 195 & 4.02 & $\mathrm{P}<0.01$ \\
\hline 7 & 2,764 & 59 & 2.13 & $\mathrm{P}>0.05$ \\
\hline 8 & 2,164 & 84 & 3.88 & $\mathrm{P}<0.01$ \\
\hline 9 & 2,463 & 113 & 4.59 & $\mathrm{P}<0.01$ \\
\hline 10 & 2,462 & 58 & 2.36 & $\mathrm{P}<0.05$ \\
\hline 11 & 3,032 & 130 & 4.29 & $\mathrm{P}<0.01$ \\
\hline 12 & 3,231 & 105 & 3.25 & $\mathrm{P}<0.01$ \\
\hline 13 & 2,168 & 54 & 2.49 & $\mathrm{P}<0.05$ \\
\hline 14 & 1,492 & 125 & 8.38 & $\mathrm{P}<0.01$ \\
\hline 15 & 2,357 & 100 & 4.24 & $\mathrm{P}<0.01$ \\
\hline 16 & 3,700 & 93 & 2.51 & $\mathrm{P}>0.05$ \\
\hline 17 & 736 & 30 & 4.08 & $\mathrm{P}<0.01$ \\
\hline 18 & 922 & 68 & 7.38 & $\mathrm{P}<0.01$ \\
\hline 19 & 1,960 & 189 & 9.64 & $\mathrm{P}<0.01$ \\
\hline Total & 42,133 & 1,687 & & \\
\hline
\end{tabular}

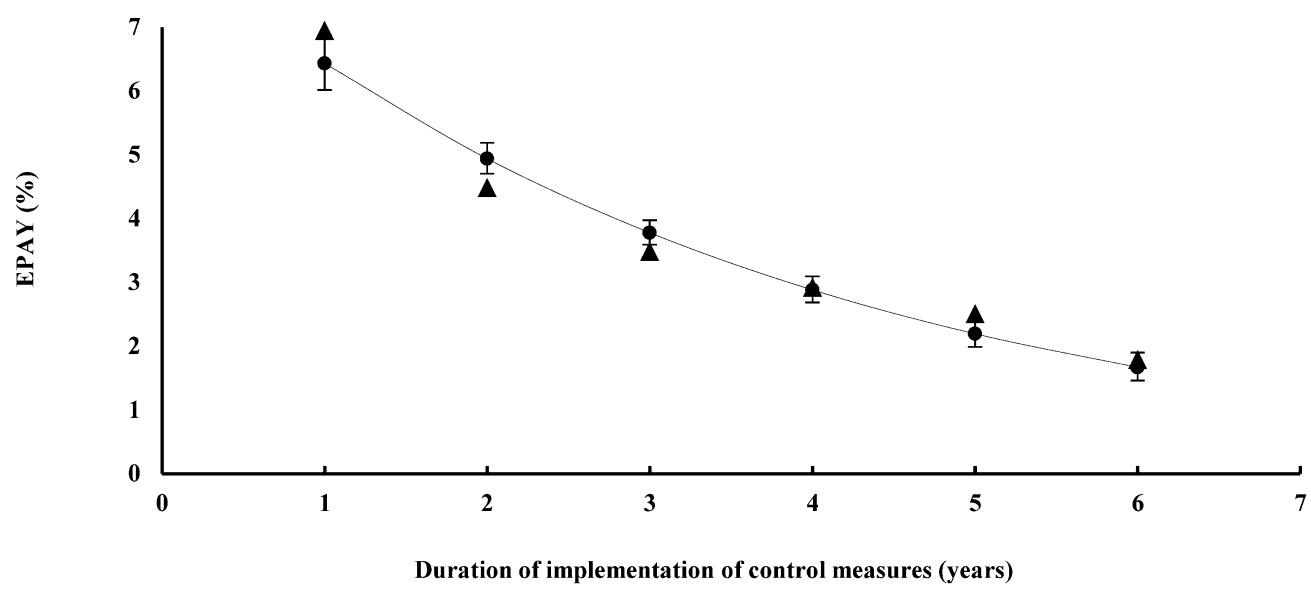

Fig. 1. The relationship between the percentage of ELISA-positive animals per year (EPAY) and the duration of implementation of MAP control measures analysed by a generalised non-linear model $(\mathrm{P}<0.01, \mathrm{OR} 0.756)$

- - expected EPAY; $\boldsymbol{\Delta}$ - observed EPAY

\section{Discussion}

In 14 out of 19 large Czech dairy herds implementing control measures to reduce MAP infection, a statistically significant reduction in the number of ELISA-positive cows detected in one year was found. Further analysis of the relationship of EPAY to the duration of the control programme indicates that the probability of detection of ELISA-positive animals in herds in which the given control measures were applied decreased between years 
by about $25 \%$ (the calculated OR was 0.756 ). The data obtained in our study assume the effectiveness of the control measures implemented in these herds in reducing MAP infection and a relatively slow reduction in the number of infected animals, which indicates the need for long-term implementation of the established measures to control MAP infection on affected farms.

In our study, cows were tested during their dry period and farmers were recommended to remove infected ELISA-positive animals from the herd immediately after delivering a calf or at the latest at the end of the forthcoming lactation. Removal of ELISApositive cows (a test-and-cull strategy) was confirmed to be effective in reducing the prevalence of MAP infection in infected dairy herds $(3,6)$. In these studies, herds with moderate to high seroprevalence at the beginning of the MAP control programme implementation were included. Collins et al. (6) described a drop in seroprevalence from $11.6 \%$ to $5.6 \%$ based on combined results from nine dairy herds during a six-year period, and a progressive decline from $26.0 \%$ to $2.3 \%$ over four years was observed by Bates et al. (3) on one dairy farm. Due to the retrospective character of our study and the sampling method, EPAY instead of herd seroprevalence was determined. In order to compare the results obtained in our study and other research, we calculated the seroprevalence from EPAY based on the calving interval. Considering the constant frequency of calving throughout the year and an average length of the calving interval of 410 days, a producing cow in a herd was tested an average of 0.89 times during one year. The seroprevalence was calculated from the equation $100 / 89 \times$ EPAY $=$ seroprevalence. This equation presumes an even distribution of ELISA-positive dams in the group of tested and untested animals. Even if this presumption were not met, the calculated seroprevalence would not change significantly, because of the high proportion of ELISA-tested animals. The calculated initial seroprevalence ranged from $0.92 \%$ (in herd 2) to $25.9 \%$ (in herd 19 ), with a median of $8.6 \%$.

A similar seroprevalence of $26 \%$ was observed for herd no. 19 and a herd described by Bates et al. (3). However, despite this similar initial level of seroprevalence, a slower decline in the number of ELISA-positive animals was observed in herd no. 19. A reduction in the number of ELISA-positive animals present in a herd could be achieved directly by their removal and indirectly by avoiding new infections. In the cited study, all animals which were highly positive by ELISA were removed from the herd before the end of the current lactation, and only low-positive and moderately-positive ELISA-tested animals were kept in the herd. The number of animals not removed from the herd gradually decreased to 2 and 0 for moderately and low ELISA-positive animals, respectively, in the last year of testing. In the present study, an average of $36.39 \%$ of ELISA-positive cows with low to moderate $\mathrm{S} / \mathrm{P}$ ratio $(\mathrm{S} / \mathrm{P} \leq 1.6)$ in herd no. 19 were retested in consecutive years of the testing period regardless of the decreasing number of detected ELISA-positive animals, as shown in Table 1, and this statistic reflects the low willingness of the farmer to remove ELISA-positive cows from the herd. Although culling of only highshedding animals has been shown to be effective in controlling MAP infection in well-managed herds (14), the higher number of ELISA-positive animals kept in herd no. 19 might have slowed the achievement of the intended effect of the control efforts. This slowing in the rate of reduction in the number of ELISA-positive animals can also be expected in other herds with a higher proportion of retested animals. Nevertheless, a decreasing trend of EPAY was observed in these herds, suggesting good calving practice with a low transmission rate. The results obtained in our study are consistent with the data disseminated by other authors showing that delayed culling of infected animals leads to effective control of infection on well-managed farms $(3,14)$.

A significant decrease in the proportion of ELISApositive cows was consistent with previously published data obtained in herds with higher initial numbers of infected animals $(3,6,12)$. No decreasing trend in the number of ELISA-positive cows was detected in five herds with initial EPAY ranging from 0.82 to $3.36 \%$ (average $2.19 \%$ ). In these herds, a constant average value of $2.01 \pm 0.92 \%$ of EPAY was observed during the whole testing period (data not shown). Most of the infected animals in MAP-infected herds are subclinically infected, with lower proportions of cows in the clinical and advanced stages of infection (15). The low number of animals in the clinical and/or advanced stages of infection in these herds may influence the willingness of farmers to remove ELISA-positive cows from the herd and to adopt the recommended control measures. All farmers were advised on the measures to be introduced into their herds to control MAP infection, but it was impossible to monitor their implementation for practical reasons. Nevertheless, it was possible to count the number of ELISA-positive animals not removed from the herd because these were retested in their next dry period. No ELISA-positive animals were detected by retesting in two herds, and the percentage of these animals in the three remaining herds did not exceed $13.33 \%$, indicating that low numbers of ELISA-positive animals were left in these herds until the next lactation. These results suggest that the failure of the EPAY in five herds to trend downwards was unlikely to have been influenced by the farmer's reluctance to remove infected animals from the herd.

Along with the test-and-cull strategy, measures to reduce infection transmission are implemented to manage MAP-infected herds. To avoid new infection of calves, exposure to an environment contaminated with adult faeces should be prevented and only colostrum or milk from ELISA-negative dams should be provided. In well-managed herds with low transmission rates, the test-and-cull strategy successfully reduces the seroprevalence $(12,14)$. General recommendations for calf rearing in large Czech dairy herds include calving in the maternity 
pen, removal of calves from the mother's environment within $2 \mathrm{~h}$, housing calves in sheds and raising replacement heifers on a remote farm. Following these principles, separating adults from young cattle and minimising the likelihood of infection transmission between them indicate well-managed herds. Separate calving of ELISA-positive cows, feeding the colostrum of ELISA-negative dams and prompt removal of calves from cows are further recommended in MAP-infected herds. Assuming the same calving practices and compliance with the control measures together with the removal of ELISA-positive animals, a decreasing trend of EPAY should be detected on all farms. Camanes et al. (5) showed in their study that the selection of control measures relevant to implement in infected herds depends on the prevalence of infected adults. These authors divided herds into low-, moderateand high-prevalence groups and defined prioritised control measures to be implemented in these herds differing in culling options. In addition to the removal of high and moderate shedders, marked calves (future shedders) should be removed from low-prevalence herds. In our study, the recommended culling options included only removing ELISA-positive cows and calves born to dams with a high $\mathrm{S} / \mathrm{P}(>1.6)$ ratio, leaving offspring of cows with moderate to low $\mathrm{S} / \mathrm{P}(\leq 1.6)$ in herds. The missing trend of decreasing EPAY in the herds with low initial numbers of ELISA-positive animals may thus reflect insufficiency in the removal of animals in these herds: culling did not include the calves of all ELISA-positive dams.

The results from herds without a detectable decreasing trend of EPAY suggest that the transmission of the infection occurs despite the implemented control measures and good herd management. This may be due to the low sensitivity of the diagnostic test used to detect infected animals (15). The likelihood of transmission of infection from infected to susceptible individuals increases with disease progression, with most infections transmitted from animals in the clinical and advanced stages. However, these animals represent a very small proportion of all infected animals in the herd and are also easily diagnosed by the ELISA test $(15,18)$. The infection can also be transmitted from subclinically infected individuals, but to a lesser extent. These animals intermittently shed low amounts of MAP bacilli in their faeces $(10,16,22)$ and can give birth to infected calves (25), thus contributing to both horizontal and vertical modes of transmission. Infection in these animals is difficult to detect, and because the sensitivity of the ELISA test for its detection is low (18), additional diagnostic tests, such as the faecal culture test and direct faecal PCR are required (11), which are more laborious and expensive and may discourage farmers from testing their animals. In addition, intermittent excretion of MAP requires repeated examination of these animals (19). Further reduction of infection pressure in herds could also be achieved by removing offspring born to infected mothers, which eliminates potentially infected animals in advance. The control measures introduced into herds should always be aligned with the objectives set by the farmer. However, more expensive diagnostic tests and preventive removal of offspring of infected cows with low ELISA results should be reserved for herds with a low prevalence of infected animals, as the same control effect can be achieved on farms with higher prevalence by cheaper measures.

The frequency of testing affects the probability of detection of an infected animal and thus the level of contamination of the environment with mycobacteria. The MAPs detected in the environment can act as an infection source for susceptible animals and their concentration should be reduced by the adoption of control measures. In our study, the cows were ELISA tested in their dry period six to two weeks before calving, which, depending on the calving interval, represents a testing frequency of 13-14 months. The recommended removal of infected cows may be delayed until the end of the forthcoming lactation. As shown by the decreasing trend of EPAY, this strategy was sufficient to control MAP infection under the conditions prevailing in large Czech dairy herds (mentioned above) and is in accordance with previously published data stating that in well-managed herds, a lower frequency with delayed removal of infected animals is sufficient to control MAP infection $(12,14)$. In addition, this testing strategy involves repeated sampling of a small group of non-milking cows housed together in a separate pen, which is more convenient for farmers than the laborious collection of samples from all cows. Moreover, the timing of pre-calving testing is advantageous given the recommended separate calving of ELISA-positive dams.

Finally, we demonstrated the effectiveness of the control measures in place to reduce MAP infection in large Czech dairy herds, with an initial percentage of ELISA-positive animals detected within one year of $\geq 3.36 \%$. Control measures included, in particular, the identification of infected animals by ELISA during the dry period every 13-14 months and their removal from the herd at the latest before the end of the forthcoming lactation, removal of calves born to dams with a high antibody titre (ELISA $\mathrm{S} / \mathrm{P}>1.6$ ) and preventing infection transmission during calving. These measures were not sufficient to reduce the number of infected animals in herds with fewer infected animals, suggesting the need for additional measures in these herds.

Conflict of Interests Statement: The authors declare that there is no conflict of interests regarding the publication of this article.

Financial Disclosure Statement: The study was supported by the Ministry of Agriculture of the Czech Republic by institutional support no. MZE-RO0518 and by grant no. QI101A094.

Animal Rights Statement: None required.

Acknowledgements: The authors thank Dr. Faldikova for the English proofreading of the manuscript. 


\section{References}

1. Aly S.S., Anderson R.J., Whitlock R.H., Fyock T.L., McAdams S.C., Byrem T.M., Jiang J., Adaska J.M., Gardner I.A.: Cost-effectiveness of diagnostic strategies to identify Mycobacterium avium subspecies paratuberculosis super-shedder cows in a large dairy herds using antibody enzyme-linked immunosorbent assays, quantitative real-time polymerase chain reaction, and bacterial culture. J Vet Diagn Invest 2012, 24, 821-832, doi: 10.1177/1040638712452107.

2. Arango-Sabogal J.C., Paré J., Labrecque O., Côté G., Roy J.P., Buczinski S., Wellemans V., Fecteau G.: Incidence of fecal excretion of Mycobacterium avium subsp. paratuberculosis in dairy cows before and after the enrolment in the Québec voluntary program. Prev Vet Med 2017, 148, 94-105, doi: 10.1016/j.prevetmed.2017.10.006.

3. Bates A., O'Brien R., Liggett S., Griffin F.: Control of Mycobacterium avium ssp. paratuberculosis infection on New Zealand pastoral dairy farms. BMC Vet Res 2019, 15, 266, doi: 10.1186/s12917-019-2014-6.

4. Beaver A., Sweeney R.W., Hovingh E., Wolfang D.R., Gröhn Y.T., Schukken Y.H.: Longitudinal relationship between fecal culture, fecal quantitative PCR, and milk ELISA in Mycobacterium avium subspecies paratuberculosis-infected cows from low-prevalence dairy herds. J Dairy Sci 2017, 100, 7507-7521, doi: 10.3168/jds.2017-12928.

5. Camanes G., Joly A., Fourichon C., Romdhane R.B., Ezanno P.: Control measures to prevent the increase of paratuberculosis prevalence in dairy cattle herds: an individual-based modelling approach. Vet Res 2018, 49, 1-13, doi: 10.1186/s13567-0180557-3.

6. Collins M.T., Eggleston V., Manning J.B.: Successful control of Johne's disease in nine dairy herds: results of a six-year field trial. J Dairy Sci 2010, 93, 1638-1643, doi: 10.3168/jds.2009-2664.

7. Fichtelová V., Králová A., Fleischer P., Babák V., Kovařčík K.: Detection of Mycobacterium avium subspecies paratuberculosis in environmental samples from infected Czech dairy herds. Vet Med-Czech 2021, 66, 1-7, doi: 10.17221/168/2020-VETMED.

8. Garcia A.B., Shallo L.: Invited review: The economic impact and control of paratuberculosis in cattle. J Dairy Sci 2015, 98, 5019-5039, doi: 10.3168/jds.2014-9241.

9. Geraghty T., Graham D.A., Mollowney P., More S.J.: A review of bovine Johne's disease control activities in 6 endemically infected countries. Prev Vet Med 2014, 116, 1-11, doi: 10.1016/ j.prevetmed.2014.06.003.

10. Jenvey C.J., Hostetter J.M., Shircliff A.L., Stabel J.R.: Relationship between the pathology of bovine intestinal tissue and current diagnostic tests for Johne's disease. Vet Immunol Immunopathol 2018, 202, 93-101, doi: 10.1016/j.vetimm. 2018.06.012.

11. Heuvelink A., Hassan A.A., van Weering H., van Engelen E., Bülte M., Akineden Ö.: An intra-laboratory cultural and real-time PCR method comparison and evaluation for detection of subclinical paratuberculosis in dairy herds. Folia Microbiol (Praha) 2017, 62, 197-205, doi: 10.1007/s12223-016-0488-1.

12. Kirkeby C., Græsbøll K., Halasa T.: Evaluating the impact of transmission mode, calibration level and farmer compliance in simulation models of paratuberculosis in dairy herds. Sci Rep 2018, 8, 9100, doi: 10.1038/s41598-018-27518-7.

13. Kovařčík K., Králová A.: Paratuberkulóza - aktuální nákazová situace v Č́R podle vyšetření bazénových vzorkủ mléka (Paratuberculosis - the current epidemiological situation in the
Czech Republic according to the examination of bulk tank milk samples - in Czech). Náš chov 2018, 78, 33-35.

14. Lu Z., Mitchell R.M., Smith R.L., Van Kessel J.S., Chapagain P.P., Schukken Y.H., Gröhn Y.T.: The importance of culling in Johne's disease control. J Theor Biol 2018, 254, 135-146, doi: 10.1016/j.jtbi.2008.05.008.

15. Magombedze G., Ngonghala C.N., Lanzas C.: Evaluation of the "iceberg phenomenon" in Johne's disease through mathematical modelling. PloS One 2013, 8, e76636, doi: 10.1371/journal.pone. 0076636.

16. Magombedze G., Shiri T., Eda S., Stabel J.R.: Inferring biomarkers for Mycobacterium avium subsp. paratuberculosis infection and disease progression in cattle using experimental data. Sci Rep 2017, 7, 44765, doi: 10.1038/srep44765.

17. McAloon C.G., Roche S., Ritter C., Barkema H.W., Whyte P., More S.J., O'Grady L., Green M.J., Doherty M.L.: A review of paratuberculosis in dairy herds - Part 1: Epidemiology. Vet J 2019, 246, 59-65, doi: 10.1016/j.tvj1.2019.01.010.

18. More S.J., Cameron A.R., Strain S., Cashman W., Ezanno P., Kenny K., Fourichon C., Graham D.: Evaluation of testing strategies to identify infected animals at a single round of testing within dairy herds known to be infected with Mycobacterium avium spp. paratuberculosis. J Dairy Sci 2015, 98, 5194-5210, doi: $10.3168 /$ jds.2014-8211.

19. Navarro-Gonzales N., Fourichon C., Blanquefort P., Delafosse A., Joly A., Ngwa-Mbot D., Biet F., Boichard D., Schibler L., Journaux L., Mees E., Guatteo R.: Longitudinal study of Mycobacterium avium spp. paratuberculosis fecal shedding patterns and concurrent serological patterns in naturally infected dairy cattle. J Dairy Sci 2019, 102, 9117-9137, doi: 10.3168/jds.2018-15897.

20. Ozsavari L., Harnos A., Lang Z., Monostori A., Strain S., Fodor I.: The impact of paratuberculosis on milk production, fertility, and culling in large commercial Hungarian dairy herds. Front Vet Sci 2020, 7, 1-9, doi: 10.3389/fvets.2020.565324.

21. Rathnaiah G., Zinniel D.K., Bannantine J.P., Stabel J.R., Gröhn Y.T., Collins M.T., Barletta R.G.: Pathogenesis, molecular genetics, and genomics of Mycobacterium avium subsp. paratuberculosis, the etiological agent of Johne's disease. Front Vet Sci, 2017, 4, 187, doi: 10.3389/fvets.2017.00187.

22. Schukken Y.H., Whitlock R.H., Wolfgang D.R., Gröhn Y.T., Beaver A., Van Kessel J.S., Zurakowski M.J., Mitchell R.M.: Longitudinal data collection of Mycobacterium avium subspecies paratuberculosis infections in dairy herds: the value of precise field data. Vet Res 2015, 46, 65, doi: 10.1186/s13567-0150187-y.

23. Smith R.L., Gröhn Y.T., Pradhan A.K., Whitlock R.H., Van Kessel J.S., Smith J.M., Wolfgang D.R., Schukken Y.H.: The effects of progressing and nonprogressing Mycobacterium avium ssp. paratuberculosis infection on milk production in dairy cows. J Dairy Sci 2016, 99, 1383-1390, doi: 10.3168/jds.2015-9822.

24. Sweeney R.W., Collins M.T., Koets A.P., McGuirk S.M., Roussel A.J.: Paratuberculosis (Johne's disease) in cattle and other susceptible species. J Vet Intern Med 2012, 26, 1239-1250, doi: 10.1111/j.1939-1676.2012.01019.x.

25. Whittington R.J., Windsor P.A.: In utero infection of cattle with Mycobacterium avium subsp. paratuberculosis: a critical review and meta-analysis. Vet J 2009, 179, 60-69, doi: 10.1016/j.tvj1.2007.08.023.

26. Windsor P.A., Whittington R.J.: Evidence for age susceptibility of cattle to Johne's disease, Vet J 2010, 184, 37-44, doi: 10.1016/j.tvj1.2009.01.007. 